\title{
Thromboresistance and functional healing in the COBRA PzF stent versus competitor DES: implications for dual antiplatelet therapy
}

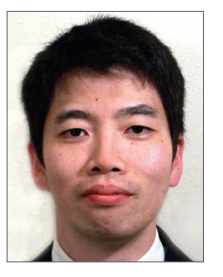

Hiroyuki Jinnouchi ${ }^{1}$, MD; Hiroyoshi Mori ${ }^{1}$, MD; Qi Cheng ${ }^{1}$, MD; Matthew Kutyna ${ }^{1}$, MS; Sho Torii ${ }^{1}, \mathrm{MD}$; Atsushi Sakamoto ${ }^{1}, \mathrm{MD}$; Liang Guo ${ }^{1}, \mathrm{PhD}$; Eduardo Acampado ${ }^{1}$, DVM; Anuj Gupta ${ }^{2}, \mathrm{MD}$; Frank D. Kolodgie ${ }^{1}, \mathrm{PhD}$; Renu Virmani ${ }^{1}$, MD; Aloke V. Finn ${ }^{1,2 *}$, MD

1. CVPath Institute, Gaithersburg, MD, USA; 2. University of Maryland, Baltimore, MD, USA

H. Jinnouchi and H. Mori contributed equally to this manuscript

This paper also includes supplementary data published online at: https:Heurointervention.pcronline.com/doi/10.4244/EIJ-D-18-00740

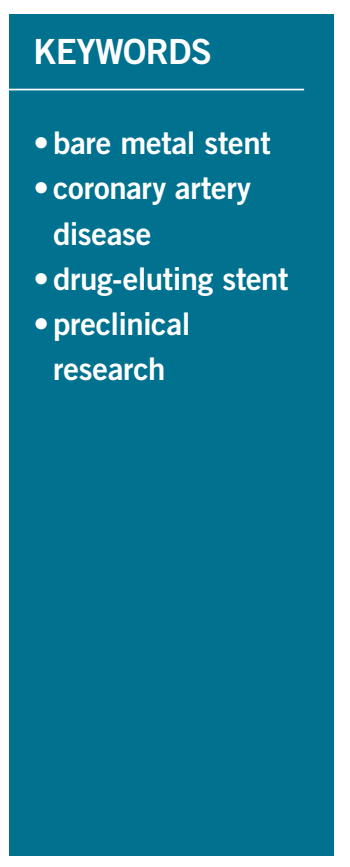

\begin{abstract}
Aims: The aim of this study was to investigate the COBRA PzF stent (C-PzF) with respect to thrombogenicity and healing versus conventional drug-eluting stents (DES) in dedicated preclinical models to evaluate their suitability for short-term dual antiplatelet therapy (DAPT).

Methods and results: To examine acute thrombogenicity, the C-PzF durable polymer drug-eluting stent (DP-DES), and a bioabsorable polymer DES (BP-DES) were compared in a porcine arteriovenous shunt model and in a rabbit model to evaluate endothelial coverage at 14 days. Barrier function at 28 days in the rabbit was assessed in the former stents as well as in a polymer-free DES (PF-BES). The number of clots by scanning electron microscopy (SEM) was significantly less in the C-PzF and DP-EES versus the BP-EES. Endothelial coverage at 14 days was significantly greater in the C-PzF versus the DP-EES and BP-EES by CD31/PECAM-1 positive area in confocal microscopy (CM) $(24.7 \%$ vs $11.9 \%$ vs $3.7 \%$, respectively) and SEM $(99.0 \%$ vs $29.6 \%$ vs $17.7 \%$, respectively). Barrier protein expression by CM for p120/vascularendothelial cadherin complex was significantly greater in the C-PzF versus the DP-EES, BP-EES, and PF-BES ( $82.6 \%$ vs $12.8 \%$ vs $14.4 \%$ vs $18.1 \%$, respectively). The percentage of Evan's Blue positive area was least in the C-PzF versus all groups ( $22.0 \%$ vs $70.7 \%$ vs $66.4 \%$ vs $55.2 \%$, respectively).
\end{abstract}

Conclusions: The C-PzF demonstrated a unique combination of thrombogenicity and healing advantages compared to contemporary DES and may be uniquely suitable for very short-term DAPT.

\footnotetext{
*Corresponding author: CVPath Institute Inc., 19 Firstfield Road, Gaithersburg, MD 20878, USA. E-mail:afinn@cvpath.org
} 


\section{Abbreviations}

$\begin{array}{ll}\text { BMS } & \text { bare metal stent } \\ \text { C-PzF } & \text { COBRA PzF } \\ \text { CoCr } & \text { cobalt-chromium } \\ \text { CM } & \text { confocal microscopy } \\ \text { DAPT } & \text { dual antiplatelet therapy } \\ \text { DES } & \text { drug-eluting stent } \\ \text { EES } & \text { everolimus-eluting stent } \\ \text { PCI } & \text { percutaneous coronary intervention } \\ \text { PF } & \text { polymer-free } \\ \text { PF-BES } & \text { polymer-free biolimus-eluting stent } \\ \text { SEM } & \text { scanning electron microscopy } \\ \text { VE } & \text { vascular-endothelial }\end{array}$

\section{Introduction}

Drug-eluting stents (DES) have revolutionised the field of percutaneous coronary intervention (PCI). Although DES reduce rates of restenosis compared with bare metal stents (BMS), they also prolong the arterial repair process which requires extended treatment with dual antiplatelet therapy (DAPT) with aspirin and a thienopyridine (e.g., clopidogrel). Overall, DAPT use is associated with increased bleeding risk. Multiple studies have documented the association of bleeding after PCI and adverse outcomes, including increased mortality ${ }^{1,2}$. It is estimated that $15 \%$ or more of patients undergoing PCI are at high risk for bleeding ${ }^{3,4}$.

Stent designs to allow shortening the duration of DAPT have become a major area of focus. Ideal adaptations would confer both antithrombotic and accelerated healing characteristics. While all current-generation stents have thin-strut metallic backbones, polymeric coatings distinguish one from another. Fluorinated polymers have shown particular promise because they have antithrombotic, antiinflammatory, and antirestenotic properties that may be conducive for curtailing DAPT ${ }^{5}$. The COBRA PzFTM coronary system (C-PzF; CeloNova Biosciences, San Antonio, TX, USA) is composed of a thin (71 $\mu \mathrm{m}$ strut thickness) strut stent made of cobalt-chromium and fluorinated Polyzene-F (PzF) polymer and coated with a unique formulation of poly(bis[trifluoroethoxy]phosphazene) without any added drugs. PzF is an inorganic, high molecular weight polymer possessing a backbone of alternating nitrogen and phosphorus atoms and trifluoroethanol side groups that can be used to coat multiple substrates including stents. The $\mathrm{C}-\mathrm{PzF}$ equipped with this novel technology exhibits a high affinity for binding serum albumin on its surface, preventing inflammatory cell, fibrinogen and platelet adhesion ${ }^{6}$. These characteristics may be beneficial for use in high bleeding risk patients where DAPT duration must be severely curtailed. In a recent clinical study, the C-PzF achieved a pre-specified performance goal for target vessel failure with infrequent late myocardial infarction and no stent thrombosis as compared with $\mathrm{BMS}^{7}$. A recent preclinical study also supported the performance of the C-PzF showing favourable antirestenotic and healing properties in the porcine model and resistance to thrombogenicity in an ex vivo shunt model as compared to $\mathrm{BMS}^{6}$.

Although recent trends favour the use of short-term DAPT (i.e., one to three months), comparative studies examining the relative thrombogenicity and healing of the C-PzF versus current-generation DES (including durable, bioabsorbable, and polymer-free versions) in preclinical models have never been performed. Therefore, the aim of this study was to evaluate these specific characteristics in these different stent types to help inform decisions regarding DAPT duration in patients receiving these devices.

\section{Editorial, see page 304}

\section{Methods}

Table 1 lists the animal models and devices used for each of these different experiments. The test arm for all studies was the C-PzF. Commercially available XIENCE Xpedition ${ }^{\circledR}$ (Abbott Vascular, Santa Clara, CA, USA) durable polymer everolimus-eluting stents (DP-EES) and SYNERGYTM (Boston Scientific, Marlborough, MA, USA) bioabsorbable polymer everolimus-eluting stents (BP-EES) were compared. Additionally, the BioFreedom ${ }^{\mathrm{TM}}$ (Biosensors, Newport Beach, CA, USA) polymer-free biolimuseluting stent (PF-BES) was added in a barrier function study.

Supplementary Appendix 1 shows details of the methods; Supplementary Table 1 provides device descriptions.

\section{Results \\ ACUTE THROMBOGENICITY IN A PORCINE ARTERIOVENOUS SHUNT MODEL}

There was no evidence of blood coagulation or platelet function abnormalities in any of the animals studied. Additionally, the measures of coagulation were similar in all shunt runs (Supplementary Table 2).

Table 1. Summary of animal model and stents tested.

\begin{tabular}{|c|c|c|c|c|}
\hline \multicolumn{2}{|c|}{ Type of study } & Thrombogenicity study & Endothelial coverage study & Barrier function study \\
\hline \multicolumn{2}{|l|}{ Model } & Ex vivo AV shunt model & In vivo stent implantation model & In vivo stent implantation model \\
\hline \multicolumn{2}{|l|}{ Animal } & Porcine & Rabbits & Rabbits \\
\hline \multicolumn{2}{|l|}{ Period } & 1 hour & 14 days & 28 days \\
\hline \multicolumn{2}{|c|}{ Number of animals } & 4 & 9 & 8 \\
\hline \multirow[t]{4}{*}{ Type of stent } & 1 & C-PzF $(n=8)$ & C-PzF $(n=6)$ & C-PzF $(n=4)$ \\
\hline & 2 & DP-EES $(n=8)$ & DP-EES $(n=6)$ & DP-EES $(n=4)$ \\
\hline & 3 & BP-EES $(n=8)$ & BP-EES $(n=6)$ & BP-EES $(n=4)$ \\
\hline & 4 & NA & NA & PF-BES $(n=4)$ \\
\hline
\end{tabular}

AV: arteriovenous; BP-EES: biodegradable polymer everolimus-eluting stent; C-PzF: COBRA PzF; DP-EES: durable polymer everolimus-eluting stent; NA: not applicable; PF-BES: polymer-free biolimus-eluting stent 
Table 2 summarises the results of platelet adhesion by $\mathrm{CM}$ and SEM. Figure 1 and Figure 2 show representative SEM and CM images with immunofluorescent staining against dual platelet markers $(\mathrm{CD} 61 / 42 \mathrm{~b})$ in the C-PzF, DP-EES, and BP-EES. When total platelet fluorescence area was normalised to stent surface area, the C-PzF had significantly greater platelet adhesion versus DP-EES, whereas there was no significant difference between the C-PzF and BP-EES. However, the number of clots counted by SEM was significantly less in the C-PzF than BP-EES, whereas there was no significant difference between the C-PzF and DP-EES.

Table 2 lists the results of immunofluorescent staining against a neutrophil marker (PM-1) and a monocyte marker (CD14) by $\mathrm{CM}$; Figure 3 shows representative images from each group. There was significantly less area of PM-1 positive staining in C-PzF and DP-EES versus BP-EES, whereas there was no significant difference between C-PzF and DP-EES. Similarly, CD14 immunostaining area showed significantly less staining in C-PzF and DP-EES as compared to BP-EES, whereas C-PzF was comparable to DP-EES.

\section{ENDOTHELIAL COVERAGE IN AN IN VIVO RABBIT MODEL AT 14 DAYS}

All animals survived the study's in-life phase. Angiography revealed no evidence of dissection or thrombosis in any of the stents. Endothelial coverage was evaluated by CM using an antibody against the endothelial surface marker CD31 (PECAM-1), a non-specific marker for endothelial cell coverage. Table 3 summarises the results of endothelial coverage by $\mathrm{CM}$ and SEM and Figure 4 shows representative SEM and $\mathrm{CM}$ images. C-PzF showed significantly greater strut coverage in terms of quantification of endothelial coverage above struts by SEM versus BP-EES and DP-EES. By CM, the percent of CD31 expression above struts as evaluated by CD31/PECAM-1 staining was significantly greater for C-PzF versus BP-EES and DP-EES. With regard to evaluation of macrophages, the RAM-11 positive area was significantly less in C-PzF when compared to DP-EES and BP-EES, as shown in Table 3.

Figure 5 shows representative CM images with immunofluorescent staining against macrophages (RAM-11) in each of the groups.

\section{BARRIER FUNCTION AND EXPRESSION IN IN VIVO RABBIT MODEL AT 28 DAYS}

All animals survived the study's in-life phase. Angiography revealed no evidence of dissection or thrombosis in any of the stents. Endothelial barrier function was evaluated at 28 days by Evans Blue dye staining (to evaluate endothelial permeability within the stents) and by CM for p120/vascular-endothelial (VE)cadherin complex which should co-localise at cell borders in areas with functioning endothelial barriers. One animal died during stent explant. Therefore, there were no Evans Blue uptake data for one BP-EES and one PF-BES. Table 4 and Supplementary Table 3 summarise the results of the endothelial barrier function study

Table 2. Thrombogenicity study in ex vivo arteriovenous shunt models.

\begin{tabular}{|c|c|c|c|c|c|c|}
\hline & $\begin{array}{l}\text { C-PzF Mean } \\
\text { (95\% CI) }\end{array}$ & $\begin{array}{l}\text { DP-EES Mean } \\
(95 \% \mathrm{CI})\end{array}$ & $\begin{array}{l}\text { BP-EES Mean } \\
\text { (95\% CI) }\end{array}$ & $\begin{array}{l}\text { C-PzF vs } \\
\text { DP-EES }\end{array}$ & $\begin{array}{l}\text { C-PzF vs } \\
\text { BP-EES }\end{array}$ & $\begin{array}{l}\text { DP-EES vS } \\
\text { BP-EES }\end{array}$ \\
\hline $\begin{array}{l}\text { Percent } \mathrm{CD} 42 \mathrm{~b} / \mathrm{CD} 61 \text { positive area } \\
\text { of total stent strut }(\%)\end{array}$ & $\begin{array}{c}22.60 \\
(14.26-35.83)\end{array}$ & $\begin{array}{c}7.94 \\
(5.00-12.58)\end{array}$ & $\begin{array}{c}16.39 \\
(10.34-25.99)\end{array}$ & 0.003 & 0.166 & 0.012 \\
\hline Number of clots by SEM & $1.67(0.94-2.97)$ & $0.875(0.36-2.13)$ & $5.18(3.05-8.79)$ & 0.153 & 0.017 & 0.006 \\
\hline $\begin{array}{l}\text { PM-1 positive cell density } \\
\text { (number } / \mathrm{mm}^{2} \text { ) }\end{array}$ & $\begin{array}{c}69.66 \\
(35.71-135.89)\end{array}$ & $\begin{array}{c}58.76 \\
(30.12-114.62)\end{array}$ & $\begin{array}{c}365.66 \\
(187.45-713.28)\end{array}$ & 0.459 & 0.008 & 0.007 \\
\hline $\begin{array}{l}\text { CD14 positive cell density } \\
\text { (number/mm²) }\end{array}$ & $\begin{array}{c}49.75 \\
(14.74-84.76)\end{array}$ & $\begin{array}{c}38.75 \\
(3.74-73.76)\end{array}$ & $\begin{array}{c}211.75 \\
(176.74-246.76)\end{array}$ & 0.415 & $<0.001$ & $<0.001$ \\
\hline
\end{tabular}

BP-EES: biodegradable polymer everolimus-eluting stent; C-PzF: COBRA PzF; DP-EES: durable polymer everolimus-eluting stent; SEM: scanning electron microscopy

Table 3. Endothelial coverage study in rabbit model at 14 days.

\begin{tabular}{|c|c|c|c|c|c|c|}
\hline & C-PzF & DP-EES & BP-EES & $\begin{array}{l}\text { C-PzF vs } \\
\text { DP-EES }\end{array}$ & $\begin{array}{l}\text { C-PzF vs } \\
\text { BP-EES }\end{array}$ & $\begin{array}{c}\text { DP-EES vS } \\
\text { BP-EES }\end{array}$ \\
\hline $\begin{array}{l}\text { CD31/PECAM-1 positive area above } \\
\text { struts }(\%)\end{array}$ & $\begin{array}{c}24.70 \\
(17.42-57.33)\end{array}$ & $\begin{array}{c}11.89 \\
(1.56-17.82)\end{array}$ & $\begin{array}{c}3.74 \\
(1.07-8.10)\end{array}$ & $<0.001$ & 0.003 & 0.098 \\
\hline $\begin{array}{l}\text { CD31/PECAM-1 area between } \\
\text { struts (\%) }\end{array}$ & $\begin{array}{c}27.35 \\
(16.11-49.57)\end{array}$ & $\begin{array}{c}10.97 \\
(1.47-20.85)\end{array}$ & $\begin{array}{c}4.58 \\
(2.69-12.57)\end{array}$ & 0.006 & 0.006 & 0.438 \\
\hline $\begin{array}{l}\text { RAM-11 positive cell density } \\
\text { (number/mm²) }\end{array}$ & $\begin{array}{c}61.5 \\
(19.00-150.5)\end{array}$ & $\begin{array}{c}199.50 \\
(143.50-313.75)\end{array}$ & $\begin{array}{c}310.00 \\
(255.00-371.00)\end{array}$ & 0.001 & $<0.001$ & 0.041 \\
\hline $\begin{array}{l}\text { Percent of coverage above strut by } \\
\text { SEM (\%) }\end{array}$ & $\begin{array}{c}99.03 \\
(90.00-99.79)\end{array}$ & $\begin{array}{c}29.57 \\
(18.37-33.79)\end{array}$ & $\begin{array}{c}17.72 \\
(7.92-21.25)\end{array}$ & $<0.001$ & $<0.001$ & 0.01 \\
\hline $\begin{array}{l}\text { Percent of coverage between struts } \\
\text { by SEM (\%) }\end{array}$ & $\begin{array}{c}100.00 \\
(95.73-100.00)\end{array}$ & $\begin{array}{c}87.50 \\
(83.64-89.27)\end{array}$ & $\begin{array}{c}74.22 \\
(70.00-80.78)\end{array}$ & $<0.001$ & $<0.001$ & 0.001 \\
\hline
\end{tabular}




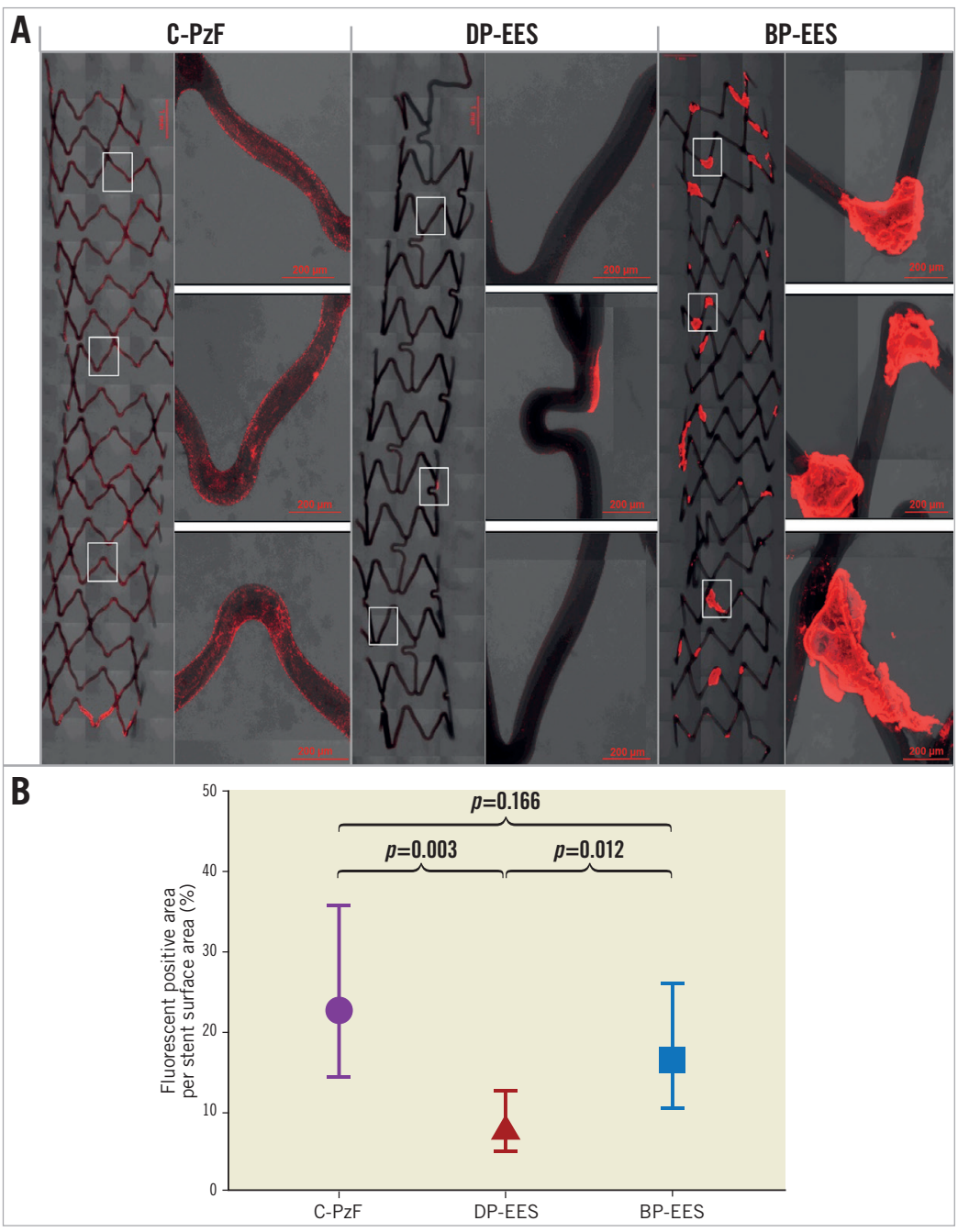

Figure 1. Representative images of CM using antibodies against CD62/42b in the swine arteriovenous shunt models. A) The left-hand images in each stent are low-power images, whereas the right-hand images are high-power images that correspond to white boxes at upper, middle and lower positions in the low-power images. $C$-PzF showed thin platelet adhesion labelled by CD62/42b immunostaining. However, there were no larger areas of clumping consistent with platelet aggregation, whereas BP-EES exhibited clots of platelet as compared with C-PzF and DP-EES. Additionally, there was much less platelet adhesion in DP-EES. B) Graph showing fluorescent positive area per stent surface. Data are presented as mean \pm standard deviation for each group and p-values are based on nested generalised linear mixed models to adjust for variations between the shunt runs. BP-EES: biodegradable polymer everolimus-eluting stent; C-PzF: COBRA PzF; DP-EES: durable polymer everolimus-eluting stent

Table 4. Barrier function study in rabbit model at 28 days.

\begin{tabular}{|c|c|c|c|c|c|c|c|}
\hline & C-PzF & DP-EES & BP-EES & PF-BES & $\begin{array}{l}\text { C-PzF vs } \\
\text { DP-EES }\end{array}$ & $\begin{array}{l}\text { C-PzF vs } \\
\text { BP-EES }\end{array}$ & $\begin{array}{l}\text { C-PzF vs } \\
\text { PF-BES }\end{array}$ \\
\hline $\begin{array}{l}\text { Percentage of co-localised VE-cadherin } \\
\text { and p120 above struts (\%) }\end{array}$ & $\begin{array}{c}82.61 \\
(36.09-95.55)\end{array}$ & $\begin{array}{c}12.81 \\
(10.20-18.74)\end{array}$ & $\begin{array}{c}14.40 \\
(7.77-29.62)\end{array}$ & $\begin{array}{c}18.12 \\
(10.48-52.53)\end{array}$ & $<0.001$ & $<0.001$ & 0.026 \\
\hline $\begin{array}{l}\text { Percentage of co-localised VE-cadherin } \\
\text { and } p 120 \text { between struts (\%) }\end{array}$ & $\begin{array}{c}78.30 \\
(32.40-95.80)\end{array}$ & $\begin{array}{c}15.70 \\
(12.86-20.72) \\
\end{array}$ & $\begin{array}{c}15.49 \\
(7.52-30.84)\end{array}$ & $\begin{array}{c}18.92 \\
(9.35-53.07)\end{array}$ & $<0.001$ & $<0.001$ & 0.039 \\
\hline $\begin{array}{l}\text { Percentage of Evan's Blue positive } \\
\text { area }\end{array}$ & $\begin{array}{c}22.02 \\
(9.86-57.09)\end{array}$ & $\begin{array}{c}70.68 \\
(58.17-76.54)\end{array}$ & $\begin{array}{c}66.43 \\
(62.32-71.43)\end{array}$ & $\begin{array}{c}55.19 \\
(50.38-61.73)\end{array}$ & 0.03 & 0.033 & 0.098 \\
\hline $\begin{array}{l}\text { Percent of coverage above strut } \\
\text { by SEM (\%) }\end{array}$ & $\begin{array}{c}99.58 \\
(99.48-99.90) \\
\end{array}$ & $\begin{array}{c}57.12 \\
(49.18-77.31) \\
\end{array}$ & $\begin{array}{c}49.91 \\
(46.65-56.52)\end{array}$ & $\begin{array}{c}65.29 \\
(53.17-80.57) \\
\end{array}$ & $<0.001$ & $<0.001$ & $<0.001$ \\
\hline $\begin{array}{l}\text { Percent of coverage between struts } \\
\text { by SEM }(\%)\end{array}$ & $\begin{array}{c}99.72 \\
(99.65-99.93)\end{array}$ & $\begin{array}{c}66.06 \\
(58.08-83.27)\end{array}$ & $\begin{array}{c}58.22 \\
(55.63-64.95)\end{array}$ & $\begin{array}{c}73.85 \\
(62.21-87.50)\end{array}$ & $<0.001$ & $<0.001$ & $<0.001$ \\
\hline
\end{tabular}

BP-EES: biodegradable polymer everolimus-eluting stent; C-PzF: COBRA PzF; DP-EES: durable polymer everolimus-eluting stent; PF-BES: polymer free biolimus-eluting stent; SEM: scanning electron microscopy; VE: vascular-endothelial 


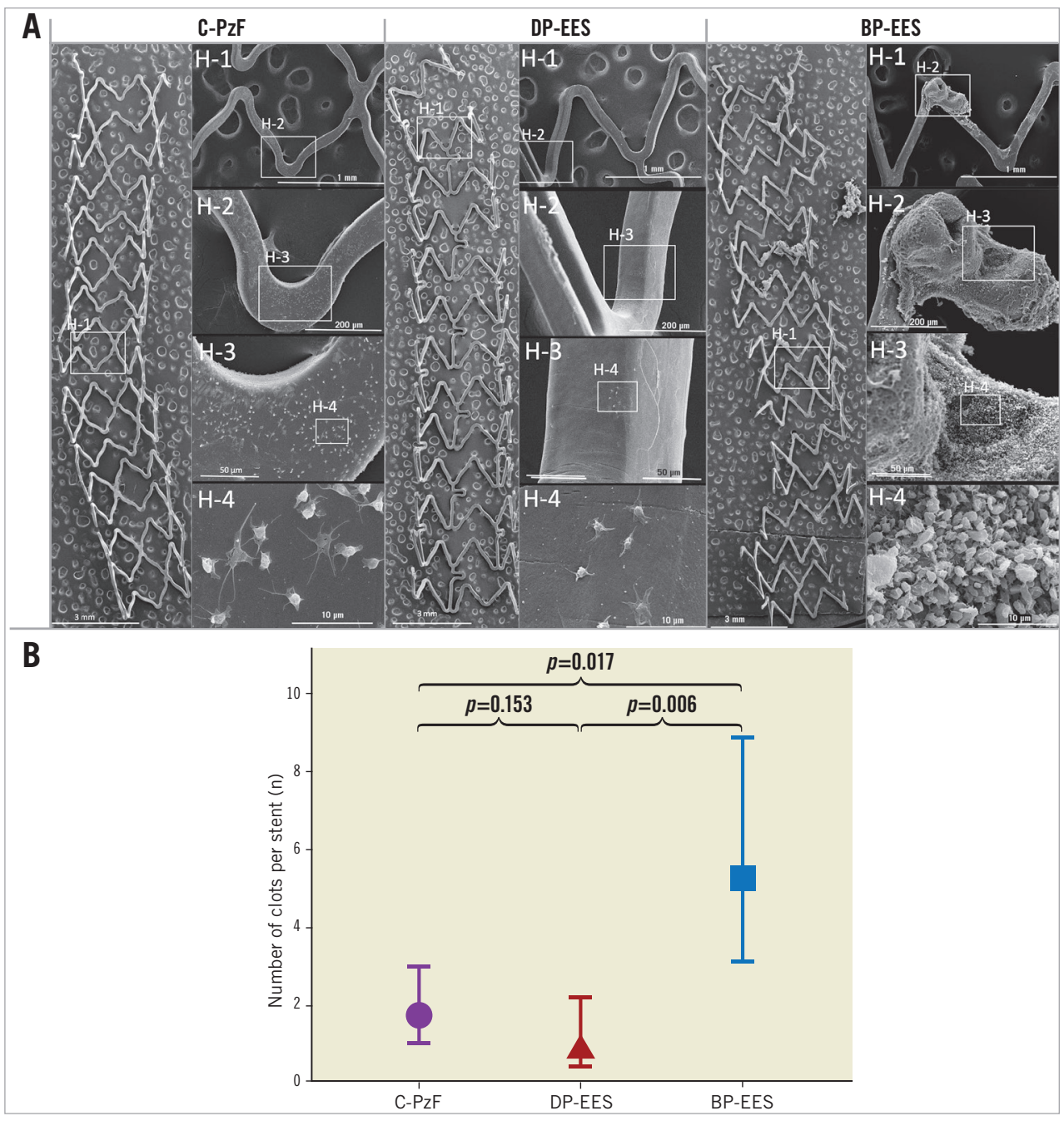

Figure 2. Representative SEM images in a swine arteriovenous shunt model. A) On the left are representative low-power (15x magnification) images of each stent, whereas on the right are high-power images (H-1: 50x; H-2: 200x; H-3: 600x; H-4: 4,000x) that correspond to white boxes in the low-power images. C-PzF and DP-EES showed minimal platelet aggregation on the strut surfaces with no larger clots in C-PzF and DP-EES, whereas BP-EES showed some clot formation. B) The number of clots per stent by SEM was significantly less in C-PzF and $D P$-EES as compared to BP-EES. Data are presented as mean \pm standard deviation for each group and p-values are based on nested generalised linear mixed models to adjust for variations between the shunt runs. BP-EES: biodegradable polymer everolimus-eluting stent; C-PzF: COBRA PzF; DP-EES: durable polymer everolimus-eluting stent; SEM: scanning electron microscopy

by Evans Blue, CM and SEM. The area of Evans Blue uptake was less in $\mathrm{C}-\mathrm{PzF}$ as compared to DP-EES and BP-EES, indicating less endothelial permeability in C-PzF. Percent of co-localisation between VE-cadherin and p120 as evaluated by CM was significantly greater in $\mathrm{C}-\mathrm{PzF}$ compared to the other three stents. Additionally, C-PzF showed a significantly greater percent of endothelial coverage above struts by SEM versus all other groups. Figure 6 shows representative images (Evans Blue, SEM and CM) by stent type. In addition, Figure 7 shows the higher power images of CM with corresponding high-power SEM images.

\section{Discussion}

Although short-term DAPT (i.e., one to three months) is thought to be the best solution for patients at high risk for bleeding, comparative studies examining the relative thrombogenicity and healing of different stents and their suitability for short-term DAPT have not been conducted. Here we specifically examined COBRA PzF versus current-generation DES in dedicated preclinical models to compare their relative thrombogenicity and healing characteristics. Overall, DP-EES with fluoropolymer coating demonstrated the least amount of platelet staining with regard to thromboresistance, while C-PzF demonstrated similar platelet adhesion to BP-EES. However, the number of clots $\left(>0.1 \mathrm{~cm}^{2}\right)$ was significantly smaller in C-PzF and DP-EES versus BP-EES. Similarly, with regard to acute inflammation in the same shunt model, C-PzF demonstrated significantly fewer inflammatory cells (i.e., neutrophils and monocytes) on the stent versus BP-EES and a similar degree to DP-EES. Endothelial coverage at 14 days, 


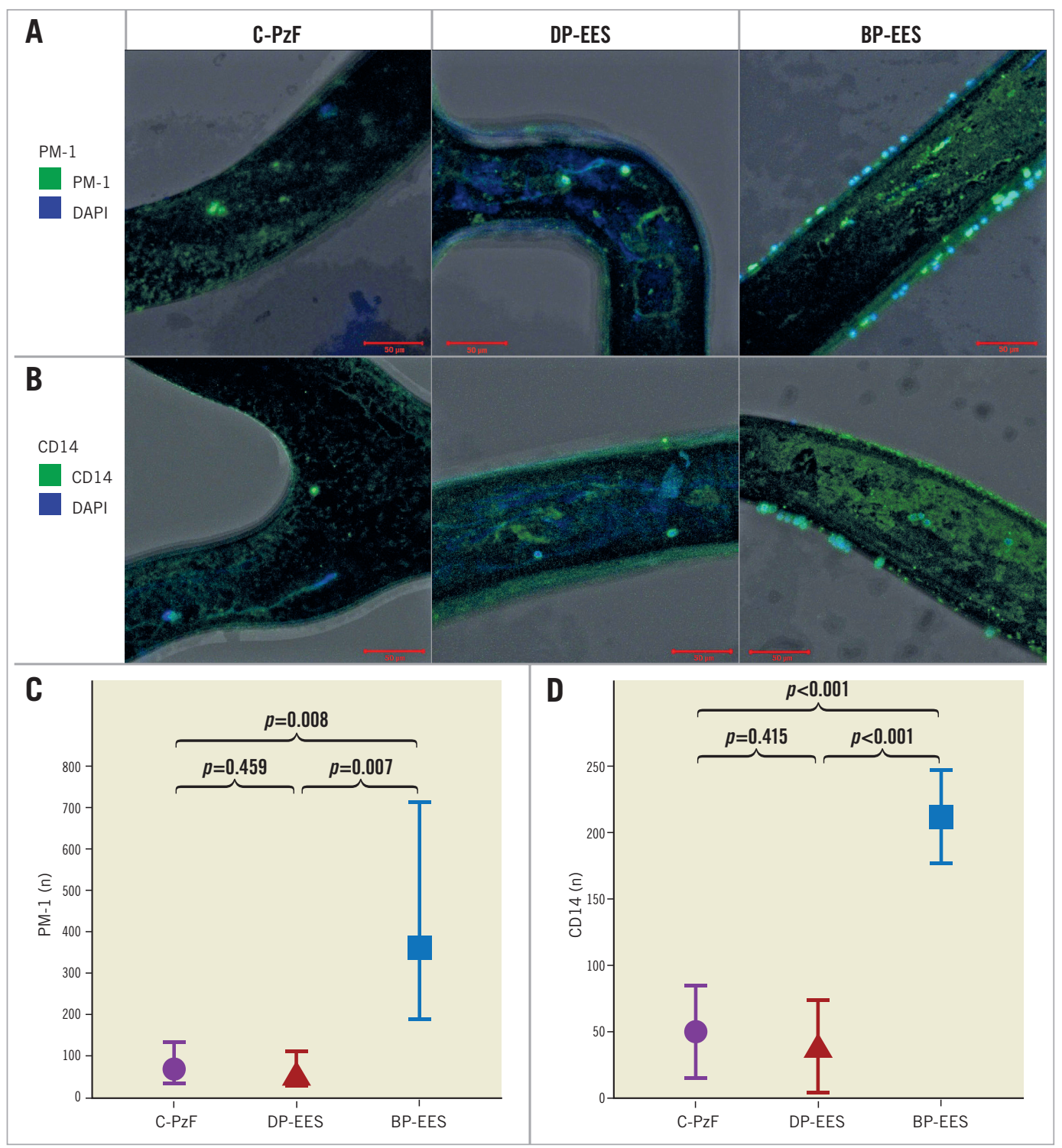

Figure 3. Representative CM images for PM-1 as a marker of neutrophils and CD14 as a marker of monocytes in a swine arteriovenous shunt model. The upper images (A) show PM-1 in each group, whereas the lower images (B) are CD14, and demonstrate that PM-1 and CD14 were less in C-PzF and DP-EES than in BP-EES. Number of PM-1 positive cells on the stent struts (C) and number of CD14 positive cells on the stent struts (D). Data are presented as mean \pm standard deviation for each group and p-values are based on nested generalised linear mixed models to adjust for variations between the shunt runs. BP-EES: biodegradable polymer everolimus-eluting stent; CM: confocal microscopy; $C-P z F$ : COBRA PzF; DP-EES: durable polymer everolimus-eluting stent

as assessed by CD31 expression and SEM analyses, was significantly greater in $\mathrm{C}-\mathrm{PzF}$ as compared to DP-EES and BP-EES. Lastly, with regard to endothelial barrier function, PzF exhibited superior endothelial barrier function and endothelial barrier protein expression (i.e., VE-cadherin and p120) as compared to DP-EES, BP-EES and PF-BES. Overall, these data suggest both antithrombotic and superior healing characteristics for $\mathrm{C}-\mathrm{PzF}$ which may be beneficial for subjects in whom short-term DAPT is necessary.

\section{ACUTE THROMBOGENICITY AND ACUTE INFLAMMATION}

Previous preclinical studies using fluorinated polymers, e.g., poly(vinylidene fluoride-co-hexafluoropropylene) (PVDF-HFP), suggested that these polymers may have thromboresistant effects by reducing platelet adhesion and activation through preferential adsorption and retention of albumin ${ }^{8}$. It has been shown that DP-EES coated with fluoropolymer (PVDF-HFP) are resistant to platelet aggregation ${ }^{5}$. PzF is also recognised as a fluorinated polymer, which is expected to show similar resistance to platelet aggregation ${ }^{9}$. In a previous porcine arteriovenous shunt study, C-PzF had significantly less platelet aggregation versus COBRABMS and $\mathrm{V}-\mathrm{BMS}^{6}$. In the current study, although the percent area of platelet staining was significantly smaller for DP-EES versus both C-PzF and BP-EES, SEM showed a lower number of clots in $\mathrm{C}-\mathrm{PzF}$ and DP-EES versus BP-EES. Likewise, inflammatory 


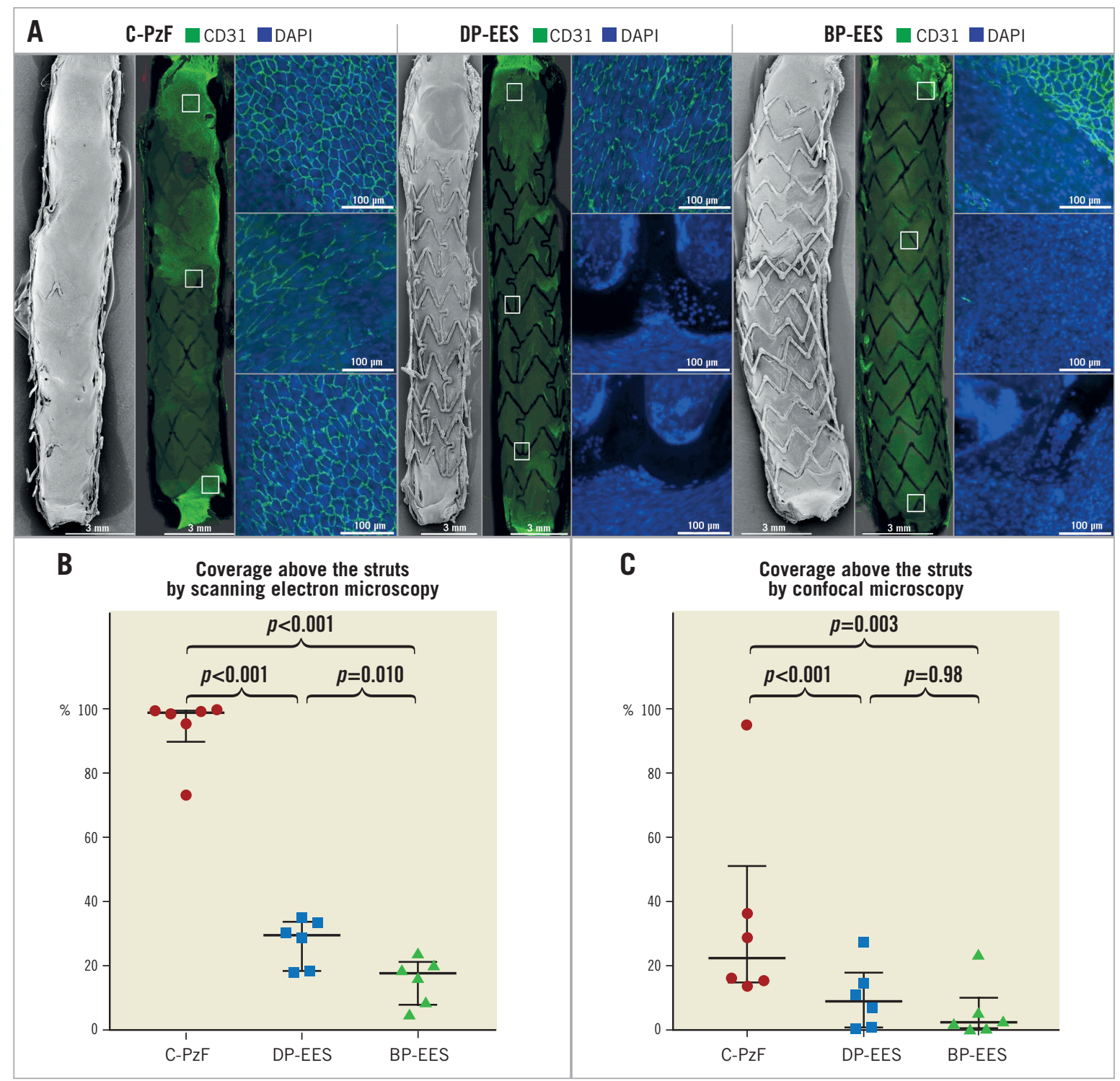

Figure 4. Representative SEM and CM images (CD31) in rabbit models at 14 days. A) Low-power (15x) images upper left, low-power (10x) CM images in the middle, and higher-power (20x) CM images on the right. Note CD31 positive area is obviously greater in C-PzF than DP-EES and BP-EES. Graphs showing endothelial coverage in SEM at 14 days (B), and CD31 expression area above strut surface by CM by stent type (C). Data are presented as median with interquartile range for each group and p-values between the groups based on generalised estimating equation method to adjust for variations between the animals. BP-EES: biodegradable polymer everolimus-eluting stent; CM: confocal microscopy; C-PzF: COBRA PzF; DP-EES: durable polymer everolimus-eluting stent; SEM: scanning electron microscopy

cell adherence was significantly less in both DP-EES and C-PzF versus BP-EES, perhaps because of the lack of platelet aggregates which when activated can recruit and activate inflammatory cells such as neutrophils and monocytes ${ }^{10}$. Despite the increase in platelet adhesion to $\mathrm{C}-\mathrm{PzF}$, fewer clots formed on the stent relative to the comparator stents. High-power SEM demonstrated a thin platelet adhesive lining without apparent aggregation, causing a uniform fluorescent signal throughout the stent. Whether this is due to differential effects of PzF versus PVDF membrane on platelet adhesion or the fact that the surface coating of C-PzF $(50 \mathrm{~nm})$ is substantially thinner than the PVDF-HPF coating on DP-EES $(8 \mu \mathrm{m})$ remains uncertain. A first step in the healing process after implantation of stents is platelet/fibrin deposition ${ }^{11}$. Minimal deposition of platelet surrounding struts without apparent aggregation is an acceptable sign for early endothelial healing. Therefore, thin platelet adhesion without apparent aggregation in C-PzF is likely not to lead to the process of thrombus formation but that of healing, as seen in the current study. Overall, our results suggest that, although platelets may adhere to the PzF surface coating, they do not aggregate, suggesting some element of thromboresistance.

\section{ENDOTHELIAL COVERAGE}

Delayed endothelial coverage after stent implantation is one of the most important causes of stent thrombosis ${ }^{12}$. In order to prevent 


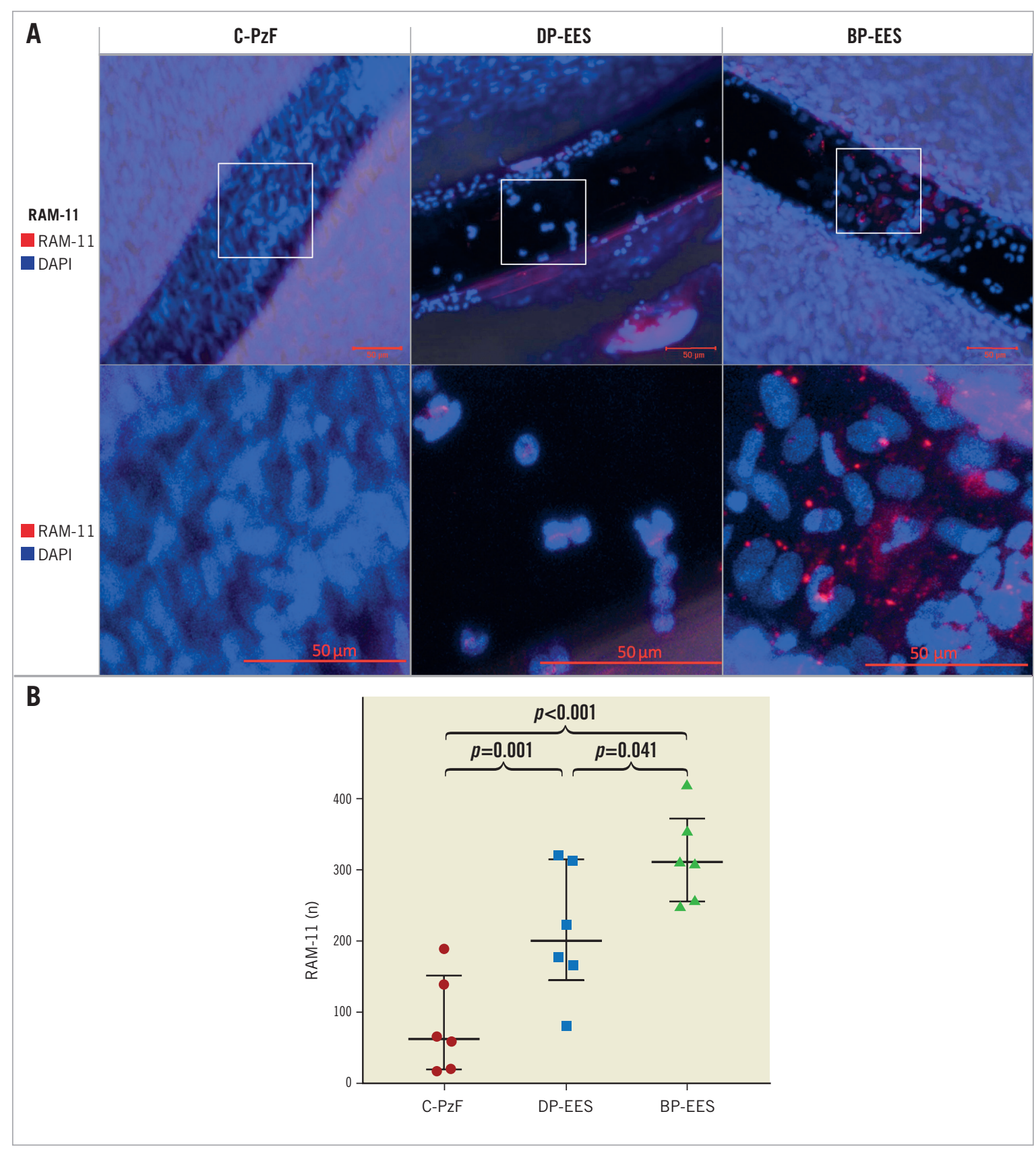

Figure 5. Representative images by CM for RAM-11 as a marker of macrophages in the rabbit model at 14 days. A) High-power images (20x) of RAM-11 positive areas on the strut surfaces. B) Graph showing RAM-11 positive area on strut surfaces by stent type. Data are presented as mean \pm standard deviation for each group and p-values comparing differences between the groups are based on a generalised estimating equation method to adjust for variations between the animals. BP-EES: biodegradable polymer everolimus-eluting stent; CM: confocal microscopy; C-PzF: COBRA PzF; DP-EES: durable polymer everolimus-eluting stent

thrombotic events after stent implantation, early endothelial coverage is crucial. The speed of endothelial coverage is influenced by contributing factors such as strut thickness, type of polymer, type of drug, and amount of drug. The thickness of stent struts is well known to influence the growth of endothelial cells through its effect on shear stress and blood flow dynamics ${ }^{13,14}$. Whereas DES elute antiproliferative agents to prevent restenosis, C-PzF does not contain a drug. Our data show that endothelial coverage in $\mathrm{C}-\mathrm{PzF}$ is superior to the commercially available DES, which may allow an even shorter duration of DAPT relative to DES. Differences in strut coverage between $\mathrm{C}-\mathrm{PzF}$ and competitor DES were probably due to the drug inhibiting endothelialisation. It is very likely that the polymer itself plays a neutral role in the speed of coverage since, in previous preclinical studies in porcine models, $\mathrm{C}-\mathrm{PzF}$ had comparable endothelial coverage to V-BMS, showing mean endothelial coverage of $98.33 \%$ even at five days by histopathology ${ }^{6}$. 


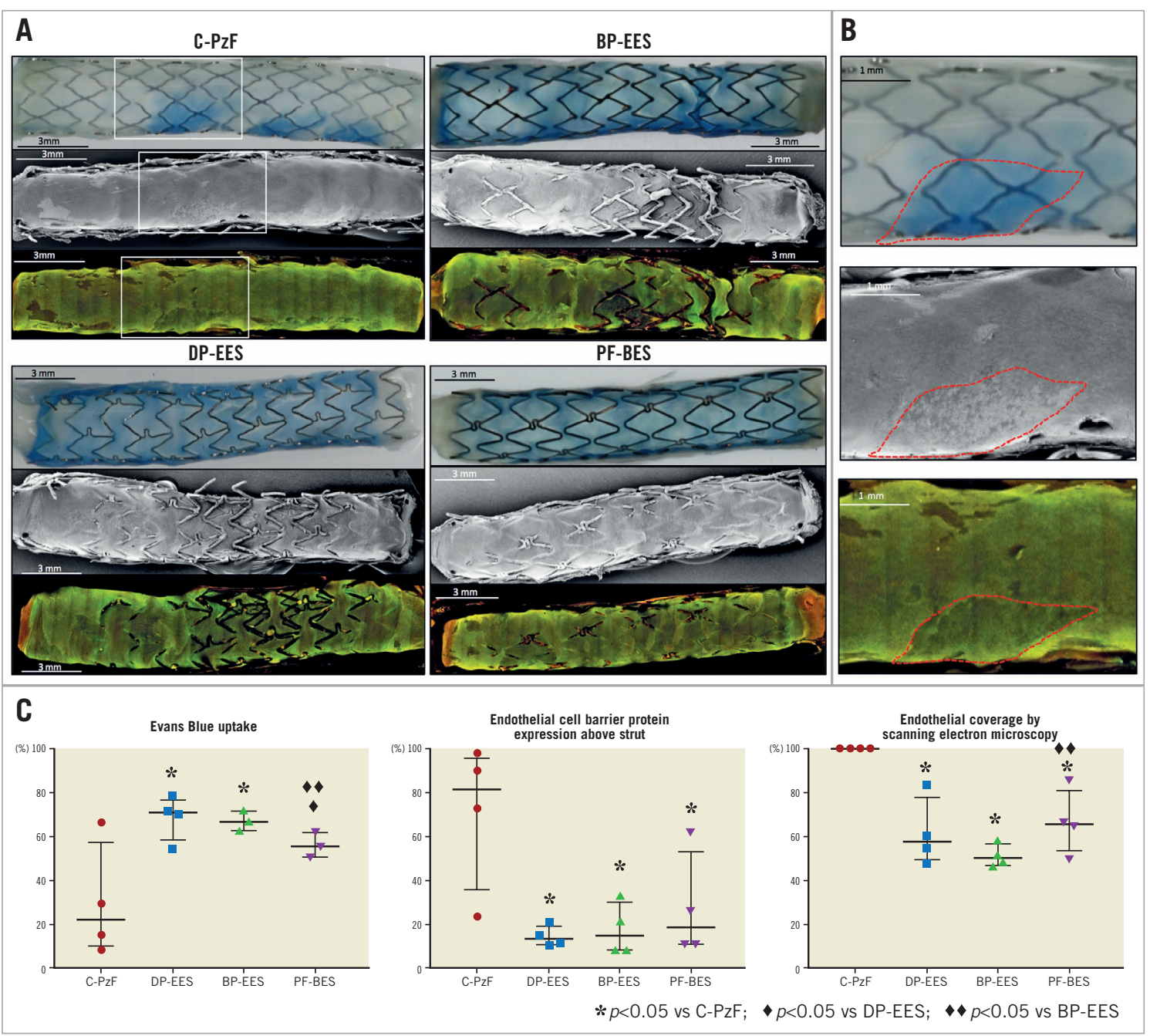

Figure 6. Representative Evans Blue, SEM and CM for VE-cadherin and 120 images in a rabbit model at 28 days. A) Upper panels show Evans Blue gross images (low-power) by stent type, the middle panels are SEM (low-power; 15x) and the lower panels are VE-cadherin and p120 expression (low-power; 10x). Note that C-PzF showed the least Evans Blue positive area, and the greatest coverage of the stent and co-localisation of VE-cadherin and p120. B) High-power images of white boxes in panel A. Red dotted lines correspond to the same positions in Evans Blue gross images, SEM, and CM. C) Graphs showing Evans Blue positive area (left), coverage above struts in SEM (middle), and co-localisation area of VE-cadherin and 120 (right). Data are presented as median with interquartile range for each group and p-values between the groups based on a generalised estimating equation method to adjust for variations between the animals. BP-EES: biodegradable polymer everolimus-eluting stent; CM: confocal microscopy; C-PzF: COBRA PzF; DP-EES: durable polymer everolimus-eluting stent; PF-BES: polymer-free biolimus-eluting stent; SEM: scanning electron microscopy; VE: vascular-endothelial

\section{BARRIER FUNCTION}

Endothelial permeability has been shown to play a role in atherosclerosis and neoatherosclerosis. Of the different types of junctional protein that exist on endothelial cells, adherens junctions play a vital role in endothelial barrier function ${ }^{15}$. Among these, VE-cadherin is essential for normal endothelial barrier function ${ }^{15}$. Administration of an anti-VE-cadherin antibody to mice resulted in increasing vascular permeability without modifying other types of interendothelial junction molecules ${ }^{16}$. In this study, VE-cadherin expression was greater in $\mathrm{C}-\mathrm{PzF}$ as compared to DP-EES, BP-EES, and PF-BES. Consistent with results of VE-cadherin and 120 co-localisation studies, Evans Blue dye staining was least in $\mathrm{C}-\mathrm{PzF}$ in all groups. In a previous preclinical study, a biodegradable polymer sirolimus-eluting stent (Ultimaster ${ }^{\mathbb{B}}$; Terumo Corp., Tokyo, Japan), which is an abluminally coated biodegradable polymer-based DES, showed better VE-cadherin expression as compared to DP-EES ${ }^{17}$. However, in that manuscript, endothelial barrier function was never tested. Here we show for the first time by Evans Blue dye staining that barrier function is disrupted in all DES compared to $\mathrm{C}-\mathrm{PzF}$ at 28 days. This is almost certainly due to drug effect, as we previously demonstrated that exposure to a mammalian target of rapamycin inhibitors (i.e., sirolimus or everolimus) leads to impaired barrier function via $\mathrm{Ca}^{2+}$ mediated activation of protein kinase $\mathrm{C}$ alpha and downstream disruption of 


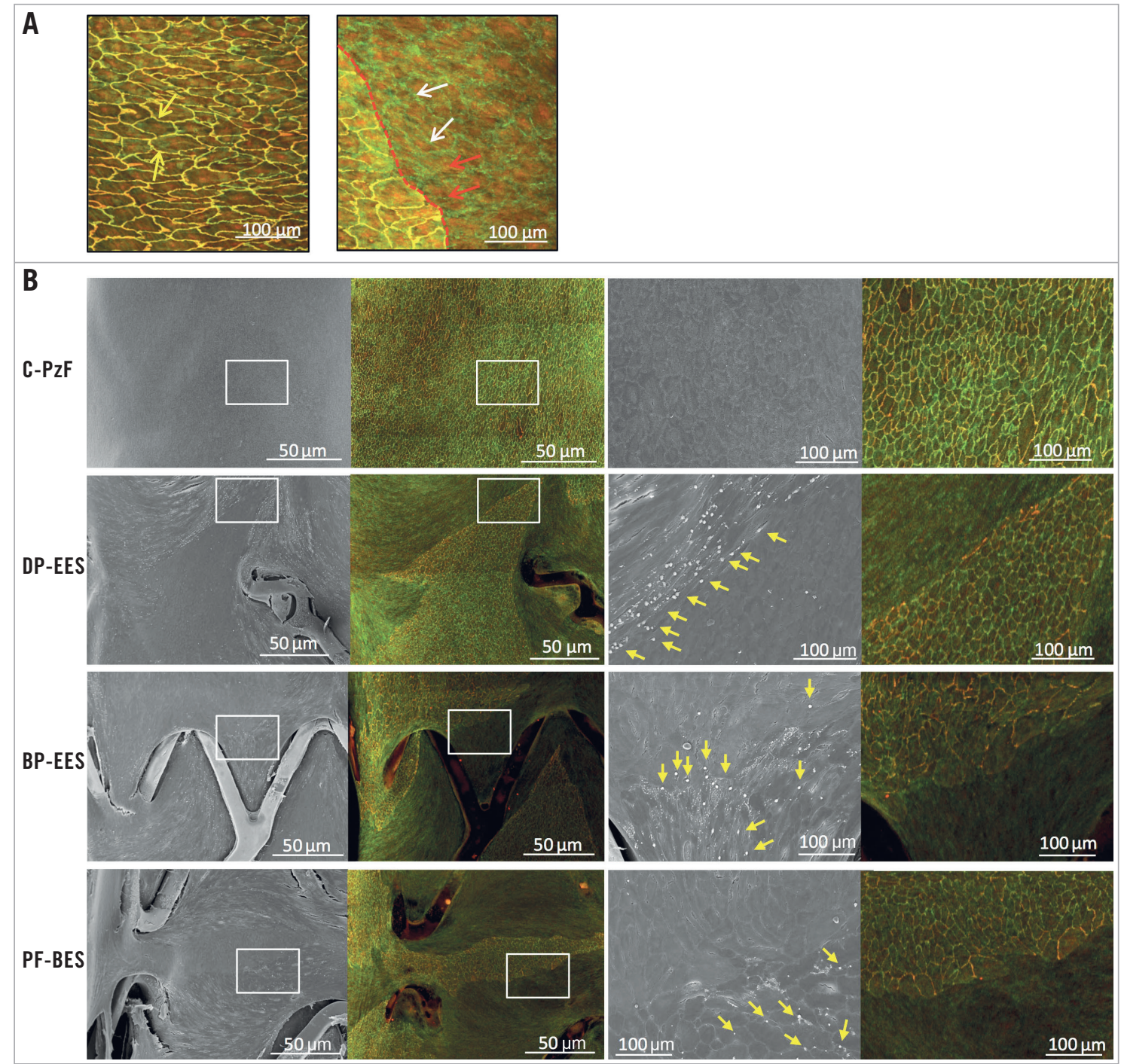

Figure 7. Endothelial barrier function in matched SEM and CM (VE-cadherin and p120) images. A) Representative high-power (40x) image with co-localisation of VE-cadherin and 120 (yellow arrows) is on the left, whereas the right panel shows dissociation of VE-cadherin (white arrows) and 120 (red arrows). Note that the border between co-localised and dissociated VE-cadherin/p120 is clearly observed by CM (red dotted line). B) The left images show matched areas by both SEM (50x) and CM (10x) using p120 and VE-cadherin antibodies. A clear border is seen between incomplete and complete co-localisation of VE-cadherin and p120 on CM images. The right images correspond to white boxes in the left images (200x in SEM and 10x in CM). In C-PzF, SEM shows areas of intact adherens junctions which are visualised on corresponding CM images showing co-localisation of 120 and VE-cadherin, whereas in DP-EES, BP-EES and PF-BES areas of non-colocalised VE-cadherin and 120 on CM show platelet and white blood cells adherence (yellow arrows) by SEM. BP-EES: biodegradable polymer everolimus-eluting stent; CM: confocal microscopy; C-PzF: COBRA PzF; DP-EES: durable polymer everolimus-eluting stent; PF-BES: polymer-free biolimus-eluting stent; SEM: scanning electron microscopy; VE: vascular-endothelial

the VE-cadherin junctional formation in vascular endothelium ${ }^{18}$. Whether other aspects of endothelial barrier function such as nitric oxide production might also be relevant towards reducing DAPT given its anti-aggregatory effects deserves further exploration.

\section{CLINICAL IMPLICATIONS}

Our preclinical data suggest that PzF coating has important benefits in terms of antithrombogenicity, reduced inflammatory reaction, and early endothelial coverage and barrier function. In fact, previous prospective clinical studies have demonstrated a very low rate of stent thrombosis ${ }^{7}$. The ongoing COBRA-REDUCE trial (NCT02594501) is examining whether, in patients undergoing coronary intervention who also require oral anticoagulation, treatment with the COBRA PzF stent plus 14-day DAPT has higher safety and non-inferior outcomes for thromboembolic events compared with a standard Food and Drug Administration-approved drug-eluting stent plus three- or six-month DAPT. Our data support such an approach, since $\mathrm{C}-\mathrm{PzF}$ showed equivalent if not better 
thromboresistance to current-generation DES and BMS as well as earlier strut coverage and return of functional healing. Clinical trials are needed to examine how short DAPT therapy could be curtailed with this novel stent system.

\section{Study limitations}

This study has some limitations. First, the results from in vivo and ex vivo models cannot be applied directly to real-world patients who have atherosclerotic coronary arteries. The atherosclerotic milieu has complex effects that may influence thrombogenicity, inflammation, and healing. Therefore, we should be cautious when extrapolating these results to the clinic. Nonetheless, we believe that these models are generally reliable to give some relative comparison of the endpoints examined between stents. Second, although our data suggest quicker and more functional endothelialisatoin for COBRA PzF, this does not mean that rates of restenosis would be equivalent to DES. Nonetheless, several previous clinical studies have shown attractive rates of target lesion revascularisation as compared to $\mathrm{BMS}^{7,19}$. Finally, PECAM-1 is not a specific marker either for endothelial cells or for platelet. However, CD31/PECAM-1 has been broadly used to evaluate endothelial cell junctions and its utility has been proven ${ }^{20-22}$. Additionally, in the process of staining, the stented artery halves were rinsed in phosphate buffered saline before staining with CD31/PECAM-1, and the pattern of staining resembles the cobblestone shape of endothelial cells not platelets. Therefore, we believe that the anti-PECAM-1 antibody detects the presence of endothelial cells (not platelets) on the surface of stents. In the current study, the coverage by SEM also supports the result of confocal microscopy using PECAM-1, showing similar trends.

\section{Conclusions}

C-PzF showed a distinctive combination of advantages when examining a combination of endpoints designed to evaluate its potential for short-term DAPT. Thromboresistance might be equivalent or superior to current-generation DP-EES and BP-EES, and healing was superior to the former stents as well as to PF-BES. $\mathrm{C}-\mathrm{PzF}$ might be of important benefit to patients requiring very short-term DAPT.

\section{Impact on daily practice}

Our data suggest that $\mathrm{C}-\mathrm{PzF}$ has characteristics which make it beneficial for short-term DAPT. The usage of C-PzF might be suitable especially for patients at high risk for bleeding.

\section{Funding}

This study was funded by CeloNova Biosciences, San Antonio, TX, USA. The design of the study, collection of data, and analysis were performed independently by CVPath personnel.

\section{Conflict of interest statement}

CVPath Institute has received institutional research support from 480 Biomedical, Abbott Vascular, ART, Biosensors International,
Biotronik, Boston Scientific, CeloNova, Claret Medical, Cook Medical, Cordis, Edwards Lifesciences, Medtronic, MicroPort, MicroVention, OrbusNeich, ReCor, SINO Medical Technology, Spectranetics, Surmodics, Terumo Corporation, W.L. Gore and Xeltis. R. Virmani has received honoraria from 480 Biomedical, Abbott Vascular, Boston Scientific, Cook Medical, Lutonix, Medtronic, Terumo Corporation and W.L. Gore, and is a consultant for 480 Biomedical, Abbott Vascular, Medtronic, and W.L. Gore. A. Finn has received honoraria from Boston Scientific, Abbott, and CeloNova. The other authors have no conflicts of interest to declare.

\section{References}

1. Giustino G, Baber U, Sartori S, Mehran R, Mastoris I, Kini AS, Sharma SK, Pocock SJ, Dangas GD. Duration of dual antiplatelet therapy after drug-eluting stent implantation: a systematic review and meta-analysis of randomized controlled trials. J Am Coll Cardiol. 2015;65:1298-310.

2. Généreux P, Giustino G, Witzenbichler B, Weisz G, Stuckey TD, Rinaldi MJ, Neumann FJ, Metzger DC, Henry TD, Cox DA, Duffy PL, Mazzaferri E, Yadav M, Francese DP, Palmerini T, Kirtane AJ, Litherland C, Mehran R, Stone GW. Incidence, Predictors, and Impact of Post-Discharge Bleeding After Percutaneous Coronary Intervention. J Am Coll Cardiol. 2015;66: 1036-45.

3. Urban P, Abizaid A, Chevalier B, Greene S, Meredith I, Morice MC, Pocock S. Rationale and design of the LEADERS FREE trial: A randomized double-blind comparison of the BioFreedom drug-coated stent vs the Gazelle bare metal stent in patients at high bleeding risk using a short (1 month) course of dual antiplatelet therapy. Am Heart J. 2013;165:704-9.

4. Morice MC, Urban P, Greene S, Schuler G, Chevalier B. Why are we still using coronary bare-metal stents? J Am Coll Cardiol. 2013;61:1122-3.

5. Otsuka F, Cheng Q, Yahagi K, Acampado E, Sheehy A, Yazdani SK, Sakakura K, Euller K, Perkins LEL, Kolodgie FD, Virmani R, Joner M. Acute Thrombogenicity of a Durable Polymer Everolimus-Eluting Stent Relative to Contemporary Drug-Eluting Stents With Biodegradable Polymer Coatings Assessed Ex Vivo in a Swine Shunt Model. JACC Cardiovasc Interv. 2015;8:1248-60.

6. Koppara T, Sakakura K, Pacheco E, Cheng Q, Zhao X, Acampado E, Finn AV, Barakat M, Maillard L, Ren J, Deshpande M, Kolodgie FD, Joner M, Virmani R. Preclinical evaluation of a novel polyphosphazene surface modified stent. Int J Cardiol. 2016;222: 217-25.

7. Cutlip DE, Garratt KN, Novack V, Barakat M, Meraj P, Maillard L, Erglis A, Jauhar R, Popma JJ, Stoler R, Silber S. 9-Month Clinical and Angiographic Outcomes of the COBRA Polyzene-F NanoCoated Coronary Stent System. JACC Cardiovasc Interv. 2017;10:160-7.

8. Szott LM, Irvin CA, Trollsas M, Hossainy S, Ratner BD. Blood compatibility assessment of polymers used in drug eluting stent coatings. Biointerphases. 2016;11:029806. 
9. Okazoe T. Overview on the history of organofluorine chemistry from the viewpoint of material industry. Proc Jpn Acad Ser B Phys Biol Sci. 2009;85:276-89.

10. Giesen PL, Rauch U, Bohrmann B, Kling D, Roque M, Fallon JT, Badimon JJ, Himber J, Riederer MA, Nemerson Y. Blood-borne tissue factor: another view of thrombosis. Proc Natl Acad Sci U S A. 1999;96:2311-5.

11. Virmani R, Kolodgie FD, Farb A, Lafont A. Drug eluting stents: are human and animal studies comparable? Heart. 2003;89: 133-8.

12. Joner M, Finn AV, Farb A, Mont EK, Kolodgie FD, Ladich E, Kutys R, Skorija K, Gold HK, Virmani R. Pathology of drug-eluting stents in humans: delayed healing and late thrombotic risk. $J \mathrm{Am}$ Coll Cardiol. 2006;48:193-202.

13. Richter Y, Edelman ER. Cardiology is flow. Circulation. 2006;113:2679-82.

14. LaDisa JF Jr, Olson LE, Douglas HA, Warltier DC, Kersten JR, Pagel PS. Alterations in regional vascular geometry produced by theoretical stent implantation influence distributions of wall shear stress: analysis of a curved coronary artery using 3D computational fluid dynamics modeling. Biomed Eng Online. 2006;5:40.

15. Mehta D, Malik AB. Signaling mechanisms regulating endothelial permeability. Physiol Rev. 2006;86:279-367.

16. Corada M, Mariotti M, Thurston G, Smith K, Kunkel R, Brockhaus M, Lampugnani MG, Martin-Padura I, Stoppacciaro A, Ruco L, McDonald DM, Ward PA, Dejana E. Vascular endothelialcadherin is an important determinant of microvascular integrity in vivo. Proc Natl Acad Sci U S A. 1999;96:9815-20.

17. Mori H, Cheng Q, Lutter C, Smith S, Guo L, Kutyna M, Torii S, Harari E, Acampado E, Joner M, Kolodgie FD, Virmani R, Finn AV. Endothelial Barrier Protein Expression in Biodegradable Polymer Sirolimus-Eluting Versus Durable Polymer Everolimus-Eluting Metallic Stents. JACC Cardiovasc Interv. 2017;10:2375-87.

18. Habib A, Karmali V, Polavarapu R, Akahori H, Cheng Q, Pachura K, Kolodgie FD, Finn AV. Sirolimus-FKBP12.6 impairs endothelial barrier function through protein kinase $\mathrm{C}-\alpha$ activation and disruption of the p120-vascular endothelial cadherin interaction. Arterioscler Thromb Vasc Biol. 2013;33:2425-31.

19. Tamburino C, Capodanno D, Di Salvo ME, Sanfilippo A, Cascone I, Incardona V, Longo G, Giacoppo D, Capranzano P, Sgroi C, Ussia G, Monaco A, La Manna A. Safety and effectiveness of the Catania Polyzene-F coated stent in real world clinical practice: 12-month results from the ATLANTA 2 registry. EuroIntervention. 2012;7:1062-8.

20. Joner M, Nakazawa G, Finn AV, Quee SC, Coleman L, Acampado E, Wilson PS, Skorija K, Cheng Q, Xu X, Gold HK, Kolodgie FD, Virmani R. Endothelial cell recovery between comparator polymer-based drug-eluting stents. $\mathrm{J} \mathrm{Am} \mathrm{Coll} \mathrm{Cardiol.}$ 2008;52:333-42.

21. RayChaudhury A, Elkins M, Kozien D, Nakada MT. Regulation of PECAM-1 in endothelial cells during cell growth and migration. Exp Biol Med (Maywood). 2001;226:686-91.

22. Gratzinger D, Barreuther M, Madri JA. Platelet-endothelial cell adhesion molecule-1 modulates endothelial migration through its immunoreceptor tyrosine-based inhibitory motif. Biochem Biophys Res Commun. 2003;301:243-9.

\section{Supplementary data}

Supplementary Appendix 1. Methods.

Supplementary Table 1. The description of all devices.

Supplementary Table 2. Summary of the mean values from the blood coagulation of all animals (PT, PPT), platelet quantification (platelet counts, platelet EST), platelet function (LTA), and activated clotting time (ACT) in a swine acute shunt model.

Supplementary Table 3. P-values of barrier function study in in vivo models.

The supplementary data are published online at:

https://eurointervention.pcronline.com/

doi/10.4244/EIJ-D-18-00740 


\section{Supplementary data}

\section{Supplementary Appendix 1. Methods}

The study protocol was approved by the Institutional Animal Care and Use Committee of the MedStar Health Research Institute.

\section{Animal models}

Two different animal models were used in this study: 1) an ex vivo porcine arteriovenous shunt model to examine acute thrombogenicity and acute inflammation ( $\mathrm{n}=4$ animals), and 2) an in vivo rabbit iliofemoral stenting model to examine endothelialisation and endothelial barrier function at both 14 and 28 days ( $\mathrm{n}=9$ animals and 8 animals, respectively).

\section{Test devices}

Three different stents were compared in an ex vivo arteriovenous shunt model for assessment of acute thrombogenicity and inflammation and in an in vivo rabbit iliofemoral stenting model for assessment of healing and inflammation at 14 days. The test arm for both studies was a cobaltchromium (CoCr) PzF stent, 3.0 x 18 mm (COBRA-PzF; CeloNova BioSciences, San Antonio, TX, USA). Commercially available XIENCE Xpedition, durable polymer everolimus-eluting stents (DP-EES) 3.0 x 18 mm (Abbott Vascular, Santa Clara, CA, USA) and SYNERGY, bioabsorable polymer everolimus-eluting stents (BP-EES), 3.0 x 20 mm (Boston Scientific, Marlborough, MA, USA) were compared. Additionally, the BioFreedom polymer-free biolimuseluting stent (PF-BES), 3.0 x 18mm (Biosensors, Newport Beach, CA, USA) was added as a comparator to the DP-EES $(3.0 \times 18 \mathrm{~mm})$ and BP-EES $(3.0 \times 16 \mathrm{~mm})$ in the in vivo rabbit 
iliofemoral model for assessment of endothelial coverage and function at 28 days (clinically the latter stent has been shown to require the shortest duration of dual antiplatelet therapy, i.e., one month, which potentially suggests an advantage with regard to healing and function).

Supplementary Table 1 shows a description of all devices used in this study.

\section{Porcine ex vivo arteriovenous shunt model}

A total of 4 healthy male Yorkshire cross domestic pigs were included in this study. A porcine $e x$ vivo arteriovenous shunt model involving a test circuit of 3 different in-line test stents was performed for 60 minutes to evaluate platelet adherence, thrombus formation, and acute inflammation in the devices. Each shunt model had 3 different stents and each animal had 2 shunt experiments for a total of $n=6$ stents per animal.

Blood activated clotting time (ACT) was kept between 150 and $190 \mathrm{~s}$ using a bolus of heparin and maintenance low-dose intravenous heparin $(100 \mathrm{IU} / \mathrm{kg})$ to minimise the effect of platelet aggregation and thrombus formation on the surface of the stents. The current study was designed to examine inherent platelet-mediated thrombus formation induced by different types of stent. At the end of each shunt run, stents were gravity perfused with Ringer's lactate until cleared of blood and then fixed in $10 \%$ neutral buffered formalin, and longitudinally bisected where one half underwent dual immunofluorescent staining.

\section{Rabbit model of iliac stent implantation}

A total of 17 (9 for the 14-day endothelialisation study and 8 for the 28-day endothelial function study) healthy male New Zealand White rabbits (3.0 to $4.0 \mathrm{~kg}$; Millbrook Laboratories, Amherst, 
MA, USA) were included in the study. Animals were given aspirin ( $40 \mathrm{mg}$ ) orally 12 hours before stent implantation and once daily until euthanasia. Stents were deployed with each iliac of an animal randomly allocated to one of 3 groups (C-PzF, DP-EES, and BP-EES) in the 14-day coverage study and one of 4 groups (C-PzF, DP-EES, BP-EES and PF-BES) in the 28-day endothelial function study. Stents (all $3.0 \mathrm{~mm}$ in diameter) were deployed at nominal pressure immediately after vessel denudation and the iliac arteries after balloon denudation. Follow-up angiography was conducted to confirm stent patency before euthanasia at 14 days in the healing study and 28 days in the endothelial function study.

Imaging procedures: confocal microscopy (CM), scanning electron microscopy (SEM) and

\section{Evans Blue test}

In the shunt model, one half of the stent which was longitudinally bisected underwent dual immunofluorescent staining using antibodies against the antiplatelet marker CD61, a marker of platelet aggregation (Immunotec, Commerce, CA, USA) and CD42b, a marker of platelet adhesion (sc-7070; Santa Cruz, Dallas, TX, USA), to capture both originating and propagated platelet thrombus as well as an antibody against the monocyte marker CD14 (Novus Biologicals, Littleton, CO, USA). The other half was immunostained using antibodies against the platelet markers CD61/CD42b and neutrophil marker PM-1 (BMA Biomedicals, Augst, Switzerland) (dilution 1:800). Both halves were examined by SEM after CM (Zeiss LSM 800; Carl Zeiss Microscopy, Jena, Germany). ZEN software (Zeiss ZEN 2012; Carl Zeiss Microscopy) quantitated the positive area of staining within predefined regions of interest. Areas staining positive for $\mathrm{CD} 61 / \mathrm{CD} 42 \mathrm{~b}\left(\mathrm{~mm}^{2}\right)$ within each stented segment were assessed. Platelet aggregate clots were counted by SEM in both stent halves. 
In the rabbit model to assess healing at 14 days after implantation of stents, one half was immunostained using CD31/PECAM-1 (Dako, Carpinteria, CA, USA), while the other half was processed for RAM-11 (Dako) and examined by SEM after completion of CM image acquisition. En face CM images were scanned both sides at 5x magnification with tiled Z-stack technology for whole surface view and at 20x magnification with single Z-stack for local regions of interest.

In the rabbit model to assess endothelial function at 28 days after implantation of stents, sterilefiltered Evans Blue dye administered i.v. was allowed to re-circulate for $1 \mathrm{hr}$ to assess endothelial permeability. Evans Blue positive area was estimated visually after being bisected. Evans Blue positive area was estimated per strut column and averaged for the entire stent. The whole stented segment was immunostained with dual staining using antibodies against VEcadherin (R\&D Systems Inc., Minneapolis, MN, USA) (dilution 1:200) and p120 (Santa Cruz)

(dilution 1:400). Subsequently, both immunostained stented halves were processed for SEM after imaging by CM. Both sides were scanned en face by CM at 5x magnification with tiled Z-stack technology for the entire stented segment surface view.

\section{Statistical analysis}

Normality of data distribution was checked by the Shapiro-Wilk test. Continuous variables were expressed as mean \pm standard deviation, median with interquartile range or estimated mean with 95\% confidence interval (CI), as appropriate. In shunt models, a nested generalised linear mixed model was used to evaluate group differences considering multiple measurements per individual. The experimental factor variables animal and shunt position were considered as nested random 
effects and stent type was considered as a fixed effect. Vessel-level comparisons were tested by a generalised estimating equation method using a linear model or gamma with log link model between C-PzF and comparators, as appropriate. SPSS software, Version 22 (IBM Corp., Armonk, NY, USA) or JMP 9 (SAS Institute, Cary, NC, USA) was used for statistical analysis. A $p$-value of $p<0.05$ was considered statistically significant. 
Supplementary Table 1. The description of all devices.

\begin{tabular}{|l|c|c|c|c|}
\hline Device & COBRA-PzF & Xience Xpedition & Synergy & BioFreedom \\
\hline Shape & & & & \\
\hline Platform & COBRA & MULTI-LINK 8 & Element & Juno Stent (SS) \\
\hline Material & CoCr & CoCr & PtCr & 316 Ltainless steel \\
\hline $\begin{array}{l}\text { Strut } \\
\text { thickness }\end{array}$ & $71 \mu \mathrm{m}$ & $81 \mu \mathrm{m}$ & $74 \mu \mathrm{m}$ & $112 \mu \mathrm{m}$ \\
\hline Drug type & - & Everolimus & Everolimus & Biolimus A9 \\
\hline Drug dose & - & $100 \mu \mathrm{g} / \mathrm{cm}{ }^{2}$ & $100 \mu \mathrm{g} / \mathrm{cm}{ }^{2}$ & $15.6 \mu \mathrm{m} / \mathrm{mm}$ \\
\hline $\begin{array}{l}\text { Materials of } \\
\text { the polymer }\end{array}$ & Polyzene-F polymer & PBMA/PVDF-HFP & PLGA & No Polymer \\
\hline $\begin{array}{l}\text { Coating type } \\
\text { Circumferential }\end{array}$ & Circumferential & Abluminal & Micro-structured \\
\hline $\begin{array}{l}\text { Coating } \\
\text { thickness }\end{array}$ & $\leq 50 \mathrm{~nm} / \mathrm{side}$ & $7-8 \mu \mathrm{m} / \mathrm{side}$ & $4 \mu \mathrm{m}$ & \\
\hline $\begin{array}{l}\text { Stent size } \\
\text { used }\end{array}$ & $3.0 \times 18 \mathrm{~mm}$ & $3.0 \times 18 \mathrm{~mm}$ & $3.0 \times 16$ or $20 \mathrm{~mm}$ & $3.0 \times 18 \mathrm{~mm}$ \\
\hline $\begin{array}{l}\text { Number of } \\
\text { stents used }\end{array}$ & 18 & 18 & 18 & 4 \\
\hline
\end{tabular}


Supplementary Table 2. Summary of the mean values from the blood coagulation of all animals (PT, PPT), platelet quantification (platelet counts, platelet EST), platelet function (LTA), and activated clotting time (ACT) in a swine acute shunt model.

\begin{tabular}{|c|c|c|c|c|c|c|}
\hline \multirow{2}{*}{ Test } & \multicolumn{3}{|c|}{$\begin{array}{c}\text { Mean } \\
(\min -\max )\end{array}$} & \multicolumn{3}{|c|}{ Fold change $(\%)$} \\
\hline & Baseline & After $1^{\text {st }}$ shunt & After $2^{\text {nd }}$ shunt & $\begin{array}{c}1^{\text {st }} \text { shunt vs. } \\
\text { baseline }\end{array}$ & $\begin{array}{c}2^{\text {nd }} \text { shunt vs. } \\
\text { baseline }\end{array}$ & $\begin{array}{c}2^{\text {nd }} \text { shunt vs. } \\
1^{\text {st }} \text { shunt }\end{array}$ \\
\hline $\begin{array}{l}\text { Prothrombin time } \\
\text { (seconds) }\end{array}$ & $\begin{array}{c}9.10 \\
(8.30-9.50)\end{array}$ & $\begin{array}{c}10.37 \\
(9.50-11)\end{array}$ & $\begin{array}{c}10.50 \\
(9.30- \\
11.30)\end{array}$ & .14 & 1.15 & 1.01 \\
\hline $\begin{array}{l}\text { PTT } \\
\text { (seconds) }\end{array}$ & $\begin{array}{c}12.27 \\
(10.50-13.40)\end{array}$ & $\begin{array}{c}54.47 \\
(30-100)\end{array}$ & $\begin{array}{c}68.73 \\
(23.70-100)\end{array}$ & 4.44 & 5.60 & 1.26 \\
\hline $\begin{array}{l}\text { Platelet count } \\
(\mathrm{x} 1,000 / \mu \mathrm{L})\end{array}$ & $\begin{array}{c}277 \\
(165-479)\end{array}$ & $\begin{array}{c}269.33 \\
(167-463)\end{array}$ & $\begin{array}{c}234.33 \\
(136-430)\end{array}$ & 0.97 & 0.85 & 0.87 \\
\hline Platelet EST & Adequate & Adequate & Adequate & $\mathrm{N} / \mathrm{A}$ & $\mathrm{N} / \mathrm{A}$ & $\mathrm{N} / \mathrm{A}$ \\
\hline $\begin{array}{l}\text { LTA }(\mathrm{ADP}=20 \mathrm{um}) \\
(\% \text { platelet aggregation })\end{array}$ & $\begin{array}{c}16.75 \\
(0-51)\end{array}$ & $\begin{array}{c}6.50 \\
(0-18)\end{array}$ & $\begin{array}{c}5.75 \\
(0-17)\end{array}$ & 0.39 & 0.34 & 0.88 \\
\hline $\begin{array}{l}\mathrm{LTA}(\mathrm{ADP}=5 \mu \mathrm{m}) \\
\% \text { platelet aggregation }\end{array}$ & $\begin{array}{c}22.25 \\
(11-30)\end{array}$ & $\begin{array}{c}10.88 \\
(6.50-14.50)\end{array}$ & $\begin{array}{c}6.50 \\
(3.50-10)\end{array}$ & 0.49 & 0.29 & 0.60 \\
\hline $\begin{array}{l}\text { ACT } \\
\text { (seconds) }\end{array}$ & $\begin{array}{c}97.00 \\
(94-99)\end{array}$ & $\begin{array}{c}152.55 \\
(136-162)\end{array}$ & $\begin{array}{c}158.77 \\
(150-168)\end{array}$ & 157 & 1.64 & 1.04 \\
\hline
\end{tabular}

Platelet EST was considered to be adequate when the platelet count was estimated to be within the reference interval.

ADP: adenosine diphosphate; LTA: light transmission aggregometry; PTT: partial thromboplastin time 
Supplementary Table 3. P-values of barrier function study in in vivo models.

\begin{tabular}{|l|r|r|r|}
\hline & $\begin{array}{l}\text { BP-EES } \\
\text { vs. PF-BES }\end{array}$ & $\begin{array}{l}\text { BP-EES } \\
\text { vs. DP-EES }\end{array}$ & $\begin{array}{l}\text { DP-EES } \\
\text { vs. PF-BES }\end{array}$ \\
\hline $\begin{array}{l}\text { Percentage of co-localised VE-cadherin and p120 above } \\
\text { struts }(\%)\end{array}$ & 0.373 & 0.522 & 0.089 \\
\hline $\begin{array}{l}\text { Percentage of co-localised VE-cadherin and p120 between } \\
\text { struts }(\%)\end{array}$ & 0.416 & 0.788 & 0.194 \\
\hline Percentage of Evans Blue positive area & 0.002 & 0.721 & 0.007 \\
\hline Percent of coverage above struts by SEM (\%) & 0.013 & 0.114 & 0.579 \\
\hline Percent of coverage between struts by SEM (\%) & 0.010 & 0.106 & 0.519 \\
\hline
\end{tabular}

BP-EES: biodegradable polymer everolimus-eluting stent; C-PzF: COBRA-PzF; DP-EES: durable polymer everolimus-eluting stent; PF-BES: polymer-free biolimus-eluting stent; SEM: scanning electron microscopy; VE: vascular-endothelial 